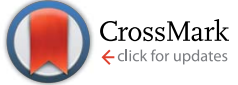

Cite this: RSC Adv., 2016, 6, 92420

\title{
Biologically synthesized crude calcium lactate as a substrate for propylene glycol production
}

\author{
M. Binczarski, ${ }^{a}$ J. Berlowska, ${ }^{\text {tb }}$ A. Stanishevsky ${ }^{c}$ and I. Witonska ${ }^{a}$ \\ Lactic acid (LA) can be obtained easily through fermentation of saccharides, and is an extremely useful \\ building block for the synthesis of valuable chemicals, including propylene glycol (PG). Catalysis is one of \\ the key elements in this platform approach. The present study focuses on PG synthesis via catalytic \\ hydrogenation of lactate ions. In the conventional biological method, separation and downstream \\ processing of pure LA account for up to $50 \%$ of production costs. Therefore, we propose using a less \\ pure solution of lactate ions as a feedstock. To this end, we have developed a new method for the \\ treatment of post-fermentation broth containing calcium lactate, obtained from sugar beet pulp. \\ Activated carbon was used for the purification of the post-fermentation broth, which was acidified to $\mathrm{pH}$ \\ 2-3. Hydrogenation of LA into PG was performed over supported metallic catalysts, based mainly on \\ ruthenium, under mild conditions. The yield of PG was satisfactory and the PG water solution obtained \\ could be used in concentrated form as a component in antifreeze.
}

Received 17th August 2016

Accepted 20th September 2016

DOI: $10.1039 / \mathrm{c} 6 \mathrm{ra} 20722 \mathrm{~g}$

www.rsc.org/advances

$27 \mathrm{MPa}$. Ford ${ }^{7}$ and Carnahan et $a .^{8}{ }^{8}$ used supported ruthenium-

\section{Introduction}

Lactic acid (LA) is one of the primary platform chemicals and can be used to synthesize a wide variety of useful products. ${ }^{1}$ By virtue of the unique presence of both hydroxyl and carboxylic acid groups, 2-hydroxypropanoic acid can participate in a wide variety of chemical reactions, including esterification, condensation, polymerization, reduction and substitution. ${ }^{2}$ Oxygenated chemicals, such as propylene glycol (PG), propylene oxide, acrylic acid and acrylate esters, or other chemical intermediates (including lactate ester plasticizers), can be made from LA, although further efforts are needed to increase the efficiency and cost-effectiveness of the process of LA production. Many studies have been conducted into the possibility of green production of LA derivatives, with one promising avenue being their production from renewable biomass. ${ }^{1}$

Catalytic transformation of LA into PG over metal based heterogeneous catalysts is of great interest to industry. The production of PG from lactate was first reported by Adkins et al. in the 1930s and 1940s, ${ }^{3-5}$ who converted neat ethyl lactate into PG over RANEY® $\mathrm{Ni}$ with yields exceeding $80 \%$ at very high pressures (>25 MPa). Broadbent et al. ${ }^{6}$ conducted the first catalytic hydrogenation of free LA using unsupported rhenium black as a catalyst. They achieved $84 \% \mathrm{PG}$ after $8 \mathrm{~h}$ at $150{ }^{\circ} \mathrm{C}$ and

Institute of General and Ecological Chemistry, Lodz University of Technology, Zeromskiego 116, 90-924, Lodz, Poland

${ }^{b}$ Institute of Fermentation Technology and Microbiology, Lodz University of Technology, Wolczanska 171/173, 90-924 Lodz, Poland. E-mail: joanna.berlowska@ p.lodz.pl

'Department of Physics, University of Alabama at Birmingham, Birmingham, AL 35294, USA based catalysts to directly hydrogenate LA at low temperature under high pressure hydrogen. Zhang et al. ${ }^{9}$ identified ruthenium on activated carbon as an extremely active catalyst for the reduction of LA at temperatures of $100-170{ }^{\circ} \mathrm{C}$ under $\mathrm{H}_{2}$ pressures of 7-14 MPa. Selectivity to PG reached $90-95 \%$ under optimal reaction conditions. Jang et al. ${ }^{10}$ performed liquidphase catalytic hydrogenation of $\mathrm{LA}\left(50 \mathrm{~mL}, 1 \mathrm{M}, 110-170{ }^{\circ} \mathrm{C}\right.$, 6-9 MPa) over various metals ( $\mathrm{Ag}, \mathrm{Co}, \mathrm{Cu}, \mathrm{Ni}, \mathrm{Pt}$ and $\mathrm{Ru}$ ) supported on $\mathrm{SiO}_{2}$. Of the catalysts tested, $\mathrm{Ru} / \mathrm{SiO}_{2}$ provided the highest PG yield, which increased with pressure. In further studies, ${ }^{11}$ liquid-phase catalytic hydrogenation of LA $(50 \mathrm{~mL}, 1$ $\left.\mathrm{M}, 110-170{ }^{\circ} \mathrm{C}, 6-9 \mathrm{MPa}\right)$ was performed over $\mathrm{Ru}$ on various carbon supports (Vulcan XC-72, ketjenblack, CNTs, CNFs, graphite). It was found that the PG yield increased with pressure and depended strongly on the type of support used. Of the catalysts tested, Ru on ketjenblack showed the highest activity.

Copper is another metal with good activity for the reduction of LA to PG. Numerous studies have demonstrated that LA can be reduced to PG on Cu-Si catalysts under mild conditions. ${ }^{12-17}$ Cortright et al. ${ }^{12}$ showed that it was possible to produce PG with high yields via the vapour-phase hydrogenation of biomassderived $\mathrm{LA}$ over $\mathrm{Cu} / \mathrm{SiO}_{2}$ catalysts. Copper-containing catalysts (copper chromite, copper-zinc hydroxysilicate and copper hydroxysilicate) exhibit high activity, due to the formation of stable, highly-dispersed particles of metallic copper during preliminary reduction. ${ }^{13-15}$ Copper-silicon catalysts have been found to have the highest selectivity for PG, at $\sim 75 \%$.

The first stage of our investigations into the catalytic reduction of LA in water phase at Lodz University of Technology was the synthesis of biological LA solutions, in which the 
concentrations of acid were around $0.5 \mathrm{M}$. We tested many catalysts, based on $\mathrm{Cu}, \mathrm{Ni}, \mathrm{Pd}, \mathrm{Ru}$ and $\mathrm{Rh}$. Each variant of the process was completed in less than 4 hours under mild temperature conditions $\left(T=130^{\circ} \mathrm{C}\right)$ and hydrogen pressure $(p$ $=3.5 \mathrm{MPa}$ ). Wet impregnation of the supports (support $=\mathrm{C}$, $\mathrm{SiO}_{2}, \mathrm{Al}_{2} \mathrm{O}_{3}$ ) was performed in aqueous solutions of metal salt $(\mathrm{M}=\mathrm{Cu}, \mathrm{Ni}, \mathrm{Pd}, \mathrm{Ru}$, and $\mathrm{Rh}$ ) to obtain $5 \% \mathrm{M} /$ support systems. Before testing, the catalysts were activated in a stream of $\mathrm{H}_{2}$ at $300{ }^{\circ} \mathrm{C}$ for $2 \mathrm{~h}$, to produce active metallic phase. The ruthenium catalysts showed the best catalytic properties for the reduction of LA to PG (5\% Ru/C: $X_{\mathrm{LA}}=94.10 \%, S_{\mathrm{PG}}=87.25 \% ; 5 \% \mathrm{Ru} / \mathrm{SiO}_{2}$ : $X_{\mathrm{LA}}=66.39 \%, S_{\mathrm{PG}}=81.62 \% ; 5 \% \mathrm{Ru} / \mathrm{Al}_{2} \mathrm{O}_{3}: X_{\mathrm{LA}}=81.24 \%, S_{\mathrm{PG}}=$ 82.31\%). Commercial 5\% Ru/C (Sigma-Aldrich, CAS 206180) catalyst produced the highest percentage of LA $\left(X_{\mathrm{LA}}=97.78 \%\right)$ and showed the best selectivity for PG $\left(S_{\mathrm{PG}}=93.25 \%\right)$. For these reasons, it was decided to use the commercial $5 \% \mathrm{Ru} / \mathrm{C}$ catalyst in further research.

Advanced and integrated hydrogenation technology enables production of PG from LA with good yields. ${ }^{18,19}$ However, it is a material-intensive process (requiring $1.25 \mathrm{~kg} \mathrm{LA} / 1.00 \mathrm{~kg}$ PG), so it is important to reduce costs and increase efficiency. The use of less pure LA as a feedstock offers one way to do this. In the conventional biological method of pure LA production, the separation and purification stages account for up to $50 \%$ of production costs. ${ }^{20}$ The sulphur-containing amino acids present in post-fermentation broths irreversibly poison metalbased catalysts (including ruthenium catalysts). Non-sulphur amino acids partially but reversibly poison the catalysts. ${ }^{21}$ It is therefore necessary to develop new methods for treating postfermentation broths containing calcium lactate, which could reduce the cost of the conventional industrial method of pure LA production.

Lactic acid can be obtained either by fermentation of renewable carbohydrates or by chemical synthesis. ${ }^{22}$ Both methods are used in commercial production. ${ }^{23}$ Due to the depletion of resources and the accumulation of environmentally hazardous chemicals, the manufacture of LA from fossil fuels is now widely considered unsustainable. Even though fermentation could replace chemical synthesis, the costs involved must be reduced. ${ }^{24}$ Low-cost cellulosic materials, such as industrial wastes, agricultural waste and forestry waste, have received much attention as possible feed stocks to substitute edible starch material, and have been recommended as costeffective alternatives for large scale fermentation. ${ }^{19,25,26}$ These substrates also show promise in terms of their chemical characteristics, levels of contaminants, possible fermentation rates, LA yields, their by-products and ability to be fermented with little or no pre-treatment. ${ }^{2}$

Because of its low lignin content, the sugar beet pulp (SBP) proposed in this paper for use as a substrate in the production of PG does not require any special biomass preparation. Substrate type is also one of the major causes of problems connected with downstream purification. The nature of the substrate may determine the degree of conversion, or which specific reagents and microbes are involved in the biological process. ${ }^{2}$ Fermentation broth contains a number of impurities as part of its cell mass, such as residual sugars, colour, nutrients and other organic acids. These impurities must be removed from the broth in order to achieve purer LA. ${ }^{25}$ The classical route for the recovery of LA from fermentation broth is based on the precipitation of calcium lactate. The filtered salt is then treated with sulphuric acid, leading to free acid and $\mathrm{CaSO}_{4}$. Additional purification steps are conducted to produce commercial grade LA. $^{27}$

In this study, we propose an approach to improve the yield of lactate ions from post-fermentation broths, which can then be catalytically reduced to PG. Two different fermentation processes are considered: separate hydrolysis and fermentation (SHF) and simultaneous saccharification and fermentation (SSF). A mixture of fermentative sugars was obtained by enzymatic hydrolysis of SBP. Simultaneous saccharification and fermentation proved particularly effective as a way of increasing the concentration of calcium lactate in the post-fermentation broths. Since it was known from the literature that potassium and calcium lactate salts cannot be converted directly to PG, but that they can be converted by the simple addition of sulphuric acid into free acid (which is then hydrogenated), ${ }^{\mathbf{9} 28}$ a simple method was found to release lactate ions from the broth. The broth was also purified of constituents containing sulphur and nitrogen heteroatoms. Catalytic reduction of the purified water solution of LA over $5 \% \mathrm{Ru} / \mathrm{C}$ catalyst produced PG under mild pressure and temperature conditions $\left(p=3.5 \mathrm{MPa}, T=130^{\circ} \mathrm{C}\right)$.

\section{Materials and methods}

\subsection{Biological material}

In both SHF and SSF processes, six lactic acid bacteria (LAB) strains (five from the Polish Collection of Microorganisms PCM and one from the American Type Culture Collection) were used: Lactococcus lactis PCM 2379, Lactobacillus acidophilus PCM 2510, Lactobacillus delbrueckii PCM 490, Lactobacillus plantarum PCM 2675, Lactobacillus brevis PCM 488, Lactobacillus plantarum ATCC 8014. Four environmental isolates were also used: Lactobacillus plantarum R, Lactobacillus plantarum HII, Lactobacillus plantarum AXD and Lactobacillus plantarum AXG, isolated from sugar beet and self-fermented grass. The environmental isolates were identified using molecular methods based on 16S rRNA gene sequencing and their accession numbers were made available in the NCBI GenBank database: KT751286, KT751287, KT751284, KT751285.

2.1.1. Preparation of inoculum. The LAB strains were activated and propagated on SBP hydrolysate. The medium was supplemented with yeast extract $\left(4.0 \mathrm{~g} \mathrm{~L}^{-1}\right)$, ammonium citrate $\left(2.0 \mathrm{~g} \mathrm{~L}^{-1}\right)$, beef extract $\left(8.0 \mathrm{~g} \mathrm{~L}^{-1}\right)$, peptone $\mathrm{K}\left(10.0 \mathrm{~g} \mathrm{~L}^{-1}\right)$, dipotassium phosphate $\left(2.0 \mathrm{~g} \mathrm{~L}^{-1}\right)$, sodium acetate $\left(5.0 \mathrm{~g} \mathrm{~L}^{-1}\right)$, magnesium sulphate $\left(0.2 \mathrm{~g} \mathrm{~L}^{-1}\right)$ and manganese sulphate $(0.05$ $\mathrm{g} \mathrm{L}^{-1}$ ), then sterilized at $120{ }^{\circ} \mathrm{C}$. The LAB cultures were incubated for $48 \mathrm{~h}$ at $37^{\circ} \mathrm{C}$. At least three cultivation passages were conducted prior to each process.

\subsection{Raw material}

Sugar beet pulp hydrolysate was produced in a semi-industrial reactor $\left(3 \mathrm{~m}^{3}\right)$ at the Sugar Factory in Dobrzelin (Poland). The 
biomass was saccharificated for $20 \mathrm{~h}$ at $50{ }^{\circ} \mathrm{C}$ using a mixture ( $1: 1)$ of two multi-enzyme preparations made by Novozymes: Viscozyme® and Ultraflo® Max ( ${ }^{\circledR} \mathrm{L} / 100 \mathrm{~kg}$ of SBP dry weight). The resulting medium contained glucose $\left(13.11 \mathrm{~g} \mathrm{~L}^{-1}\right)$, fructose (4.92 $\left.\mathrm{g} \mathrm{L}^{-1}\right)$, xylose $\left(0.65 \mathrm{~g} \mathrm{~L}^{-1}\right)$, rhamnose $\left(2.37 \mathrm{~g} \mathrm{~L}^{-1}\right)$, raffinose (22.53 $\left.\mathrm{g} \mathrm{L}^{-1}\right)$, galactose $\left(14.11 \mathrm{~g} \mathrm{~L}^{-1}\right)$ and arabinose $(10.83 \mathrm{~g}$ $\left.\mathrm{L}^{-1}\right)$. Enzyme activity was halted at the end of the process by 30 minutes of incubation at $37^{\circ} \mathrm{C}$.

\subsection{Lactic acid fermentation}

2.3.1. Separate hydrolysis and fermentation (SHF). Separate hydrolysis and fermentation was carried out in $100 \mathrm{~mL}$ Erlenmeyer flasks in $50 \mathrm{~mL}$ hydrolysate supplemented with yeast extract $\left(4.0 \mathrm{~g} \mathrm{~L}^{-1}\right)$, ammonium citrate $\left(2.0 \mathrm{~g} \mathrm{~L}^{-1}\right)$, beef extract (8.0 $\left.\mathrm{g} \mathrm{L}^{-1}\right)$, Peptone $\mathrm{K}\left(10.0 \mathrm{~g} \mathrm{~L}^{-1}\right)$, dipotassium phosphate $\left(2.0 \mathrm{~g} \mathrm{~L}^{-1}\right)$, sodium acetate $\left(5.0 \mathrm{~g} \mathrm{~L}^{-1}\right)$, magnesium sulphate $\left(0.2 \mathrm{~g} \mathrm{~L}^{-1}\right)$ and manganese sulphate $\left(0.05 \mathrm{~g} \mathrm{~L}^{-1}\right)$. The sterilized medium was inoculated with $\mathrm{LAB}$ monocultures and incubated for $48 \mathrm{~h}$ at $37{ }^{\circ} \mathrm{C}$. Sterile calcium carbonate $\left(\mathrm{CaCO}_{3}\right)$ suspension was added in selected trials to stabilize the $\mathrm{pH}$.

2.3.2. Simultaneous saccharification and fermentation (SSF). Simultaneous saccharification and fermentation was carried out in $100 \mathrm{~mL}$ Erlenmeyer flasks filled with SBP (6 g dry weight), water and $\mathrm{CaCO}_{3}$. Prior to the process, the SBP was suspended in warm water to obtain a dry matter concentration of around $12 \%(\mathrm{w} / \mathrm{v})$. After supplementation with nitrogen and mineral compounds (yeast extract, ammonium citrate, beef extract, peptone $\mathrm{K}$, dipotassium phosphate, sodium acetate, magnesium sulphate, manganese sulphate) the suspension was sterilized at $120^{\circ} \mathrm{C}$. Hydrolysis was initiated after the addition of a $1: 1$ mixture of Ultraflo Max and Viscozyme $(0.1 \mathrm{~mL} / 10 \mathrm{~g}$ SPB dry weight). The process was continued for $10 \mathrm{~h}$ at $37^{\circ} \mathrm{C}$, after which the medium was inoculated with LAB strains (without enzyme denaturation). The fermentation process was conducted for $48 \mathrm{~h}$ in the case of monocultures, and for $96 \mathrm{~h}$ in the case of mixed cultures (second inoculations were made after the first $48 \mathrm{~h}$ ).

\subsection{Lactic acid recovery and purification}

The samples were purified on activated carbon (ERCARBON GE, $2.5 \mathrm{~g} / 50 \mathrm{~mL})$ or on a mixture of activated carbon and silica $\left(m_{\text {Cakt }}\right.$ $=2.5 \mathrm{~g} / 50 \mathrm{~mL} ; m \mathrm{SiO}_{2}\left(\mathrm{SiO}_{2}, \mathrm{POCH}\right.$ Gliwice SA $\left.)=2.5 \mathrm{~g} / 50 \mathrm{~mL}\right)$. The solid adsorbent was weighed and added to a metered volume of a liquid biological sample. The mixture was stirred vigorously for 1 minute at $10{ }^{\circ} \mathrm{C}$. The supernatant was then separated by filtration and subjected to catalytic hydrogenation. The results indicated that the sample had been successfully purified.

\subsection{Propylene glycol synthesis}

Hydrogenation of LA was performed in a $50 \mathrm{~mL}$ autoclave (Parr Company) at $130{ }^{\circ} \mathrm{C}$ and under $3.5 \mathrm{MPa}$ of $\mathrm{H}_{2}$ pressure. The reactions were conducted with equal amounts of catalyst $\left(m_{\text {cat }}=\right.$ $0.5 \mathrm{~g}$ ). The mixture was stirred at $500 \mathrm{rpm}$. The autoclave was flushed with Ar, then flushed again with $\mathrm{H}_{2}$ and pressurized with $\mathrm{H}_{2}$ to $3.5 \mathrm{MPa}$. The temperature was gradually raised to 130
${ }^{\circ} \mathrm{C}$ at a heating rate of $20{ }^{\circ} \mathrm{C} \mathrm{min}^{-1}$. The reaction was sustained for 4 hours. The reaction conditions were optimized for a $5 \%$ $\mathrm{Ru} / \mathrm{C}$ catalyst (Sigma-Aldrich, CAS 206180), used for the reduction of $20 \mathrm{~mL}$ water solution of commercial LA (0.5 M, POCh Gliwice SA, p.p.a.). The biological LA samples, after purification on activated carbon (or a mixture of activated carbon and silica), were either catalytically reduced or first diluted with deionized water to a concentration of LA $0.5 \mathrm{M}$ and then reduced over 5\% $\mathrm{Ru} / \mathrm{C}$. Following the reaction, the autoclave was cooled to room temperature. The reaction mixture was then filtered and analyzed using HPLC and GC-FID techniques.

\subsection{Media analysis}

The concentration of lactate ions was measured spectrophotometrically using a D-/L-Lactic Acid Assay Kit (K-DLATE) (Megazyme). To improve the solubility of the calcium lactate, the probes were heated to $80{ }^{\circ} \mathrm{C}$ for 15 minutes.

An HPLC system (LaChrome, Merck-Hitachi) coupled to a variable wavelength UV $(210 \mathrm{~nm})$ detector was used to determine the concentration of LA. The reactant was separated on an Agilent ZORBAX SB-C18 column, with the use of mobile phase acetonitrile/phosphate buffer $=12: 88 \mathrm{v} / \mathrm{v}(\mathrm{pH}=4.5, C=0.01$ M).

To assess the concentration of free LAs in the fermented hydrolysates, they were first passed through a centrifugal ultrafilter with a cut-off mass of $3 \mathrm{kDa}$. Samples $(50 \mu \mathrm{l})$ were then transferred into Eppendorf tubes and evaporated to dryness in a vacuum centrifuge. Next, the free amino acids were converted into a phenylthiocarbamide (PTC) derivative. The derivatives were dissolved in amino acid solvent, added in portions of $(200 \mathrm{~mL})$. Samples $(5 \mu \mathrm{l})$ were analyzed using high pressure liquid chromatography (HPLC) on a PicoTag $3.9 \times 150$ mm column (Waters, USA). Quantitative calibration was performed using four concentrations of amino acid standards (Pierce Company, USA).

The concentration of PG was determined using the GC-FID technique (Hewlett Packard 5890A; Restek RTX 5 column). The operating conditions for GC-FID analysis were: injection port temperature $70{ }^{\circ} \mathrm{C}$; FID detector temperature $250{ }^{\circ} \mathrm{C}$; column oven temperature $150{ }^{\circ} \mathrm{C}$; temperature increase $15{ }^{\circ} \mathrm{C}$ $\mathrm{min}^{-1}$; carrier gas He (Linde, $99.999 \%$, flow rate $30 \mathrm{~mL} \mathrm{~min}^{-1}$ ); injection volume $1 \mu \mathrm{l}$.

The trials in each experiment were repeated in triplicate. The mean values are presented.

\section{Results and discussion}

\subsection{Fermentation processes and calcium lactate formation}

Any sugar can be used as a carbon source for the microbial production of LA. ${ }^{26,29}$ Sugar in its pure forms, such as glucose, sucrose and lactose, starchy materials from potatoes, tapioca, wheat, barley, carrot, and waste materials containing sugar, including molasses, whey, sugarcane bagasse, cassava bagasse or sugar beet, coffee husks and pulp, apple pomace, oilcakes or wheat/rice bran, may all be suitable for this purpose. Sugar beet pulp hydrolyzate has been shown to be a useful substrate for LA 
Table 1 Production of lactic acid in SHF processes

\begin{tabular}{lll}
\hline & \multicolumn{2}{l}{ Production of lactate ions $\left[\mathrm{g} \mathrm{L}^{-1}\right]$} \\
\cline { 2 - 3 } & without $\mathrm{CaCO}_{3}$ & with $\mathrm{CaCO}_{3}$ \\
\hline Lb. delbrueckii PCM 490 & $6.89 \pm 1.38$ & $11.96 \pm 0.19$ \\
L. lactis PCM 2379 & $5.54 \pm 0.02$ & $13.44 \pm 1.75$ \\
Lb. plantarum HII & $7.01 \pm 0.23$ & $12.60 \pm 0.37$ \\
Lb. acidophilus PCM 2510 & $7.62 \pm 0.44$ & $12.48 \pm 0.65$
\end{tabular}

fermentation conducted in SHF mode using $L b$. delbrueckii PCM 490, Lb. lactis PCM 2379, Lb. plantarum HII and Lb. acidophilus PCM 2510 strains (Table 1.). However, owing to the inhibitory effects of low $\mathrm{pH}$ on cell growth and LA productivity, an agent should be added to maintain a constant $\mathrm{pH}^{1}{ }^{1}$ In our experiments, the addition of $\mathrm{CaCO}_{3}$ doubled the LA yield, which reached values of 11.96-14.44 $\mathrm{g} \mathrm{L}^{-1}$ (Table 1.). This corresponded to $0.13-0.16 \mathrm{M}$ lactate concentrations. However, even higher concentrations of lactate ions are preferable for catalytic purposes. ${ }^{26}$

Whether the production of LA and its derivatives is economical depends on many factors, among the most important of which are the cost of the raw material and fermentation efficiency. ${ }^{19,29}$ Many processing costs can be reduced by using SSF. This procedure helps to increase the yield and productivity of LA. Especially in the case of lignocellulosic materials, SSF processes have advantages over SHF. Consumable sugars, such as glucose, released by lytic enzymes, are gradually converted into the end product by microorganisms. ${ }^{24}$ Carbon catabolite repression and enzyme glucose inhibition are thereby minimized. ${ }^{30,31}$ Moreover, Hofvendahl ${ }^{32}$ showed that SSF requires lower quantities of enzymes to produce LA, thus reducing production costs further. It was therefore decided to ferment the SBP (in the presence of $\mathrm{CaCO}_{3}$ ) simultaneously with enzymatic hydrolysis (Table 2). This resulted in a fourfold increase in the production of lactate ions, while using around a third of the amount of enzymes.

The main barrier to use of lignocellulose is the composition of the carbohydrates in its hydrolyzates. Hydrolysis leads to the release of hexoses and pentoses. However, most commercial LAB strains used by industry lack the ability to assimilate pentose. ${ }^{33}$ Using more than one fermenting strain can improve the efficiency of the process by $10-30 \%{ }^{34}$ The use of mixed cultures has been shown to substantially improve LA yield from fermented corn stover ${ }^{35}$ and date juice. ${ }^{34}$ This can be explained

Table 2 Production of lactic acid in SFF processes conducted with monocultures

\begin{tabular}{lll}
\hline LAB strains & Lactate ions $\left[\mathrm{g} \mathrm{L}^{-1}\right]$ & Lactate ions $\left[\mathrm{mol} \mathrm{L}^{-1}\right]$ \\
\hline Lb. delbrueckii PCM 490 & $49.16 \pm 1.14$ & $0.546 \pm 0.013$ \\
L. lactis PCM 2379 & $43.45 \pm 0.41$ & $0.482 \pm 0.005$ \\
Lb. plantarum HII & $47.11 \pm 2.15$ & $0.523 \pm 0.024$ \\
Lb. acidophilus PCM 2510 & $45.18 \pm 1.95$ & $0.502 \pm 0.022$
\end{tabular}

by greater utilization of different carbon sources and by reduced nutrient limitation. ${ }^{36}$ In our study, the concentration of lactate ions increased by $10-12 \%$ after the second fermentation step using mixed cultures (Table 3 ).

\subsection{Lactic acid recovery and purification}

Downstream processing of LA broth is extremely complicated and involves a number of steps. ${ }^{37}$ Pure LA has been commercially produced using strong acids, cation-exchange resins and solid catalysts. ${ }^{2538}$ Musahino Chemical Laboratory in Japan, CCA Biochemical BV in the Netherlands and Natureworks LLC are among the majority of large-scale LA manufacturers which have switched to fermentation technologies based on a number of downstream treatments, including precipitation, conventional filtration, acidification, carbon adsorption and evaporation. ${ }^{2}$ The separation and purification of LA from fermentation broth adds significantly to production costs. ${ }^{\mathbf{1 , 2 5}}$ The usual alternatives are: (1) precipitation of cations salts; (2) liquidliquid extraction with simultaneous lactate salt formation using a strong base and back-extraction of LA with water; (3) simultaneous acidification and esterification with alcohol followed by back-extraction with water; (4) direct removal of LA from the broth using advanced separation methods, such as adsorption, membrane separations and ion exchange. ${ }^{37}$

Two methods of LA recovery are generally employed. In the first, the clarified fermented liquor is concentrated to $32 \%$, well above crystallization point, and then acidified using sulphuric acid to obtain crude LA. Alternatively, the crude calcium salt which precipitates from the concentrated fermented liquor can be crystallized, filtered, dissolved and then acidified using sulphuric acid. ${ }^{39}$ The filtered fermented broth contains impurities such as residual sugar compounds, colour and other organic acids, which can be removed by reactive extraction, adsorption, electrodialysis or esterification-hydrolysis with distillation. ${ }^{39,40}$

Esterification can be performed efficiently through reactive distillation, using cation exchange resin columns acting as both packing and catalyst. However, the columns need to be fed with pre-purified LA. In the case of reactive extraction, adsorption, electrodialysis or conventional precipitation-filtration, on the other hand, calcium lactate washing treatments are necessary. ${ }^{39}$ The route involving quantitative precipitation of salts from the broth and separation of the solid phase requires the calcium lactate to be washed, to remove impurities retained during

Table 3 Production of lactic acid in SFF processes conducted with mixed cultures

\begin{tabular}{lll}
\hline LAB strains & Lactate ions $\left[\mathrm{g} \mathrm{L}^{-1}\right]$ & Lactate ions $\left[\mathrm{mol} \mathrm{L}^{-1}\right]$ \\
\hline $\begin{array}{l}\text { Lb. delbrueckii } \text { PCM } 490 \\
\text { Lb. plantarum ATCC } 8014\end{array}$ & $56.42 \pm 2.87$ & $0.626 \pm 0.032$ \\
$\begin{array}{l}\text { L. lactis } \text { PCM } 2379 \\
\text { Lb. plantarum AXD }\end{array}$ & $51.71 \pm 2.71$ & $0.574 \pm 0.030$ \\
$\begin{array}{l}\text { Lb. plantarum HII } \\
\text { Lb. brevis PCM 488 }\end{array}$ & $55.57 \pm 1.85$ & $0.617 \pm 0.021$ \\
Lb. acidophilus PCM 2510 & $50.35 \pm 2.29$ & $0.559 \pm 0.025$ \\
Lb. plantarum AXG & &
\end{tabular}


Table 4 Quantitative analysis of amino acids in the biological sample, before and after purification using activated carbon. Lactic fermentation was performed in SBP hydrolyzate using Lactobacillus delbrueckii PCM 490

\begin{tabular}{|c|c|c|}
\hline \multirow[b]{2}{*}{ Amino acid } & \multicolumn{2}{|c|}{ Amino acid content $\left[\mathrm{mmol} \mathrm{L}^{-1}\right]$} \\
\hline & Before purification & After purification \\
\hline Asp & $23.43 \pm 1.93$ & b.d.l. \\
\hline Glu & $47.93 \pm 4.37$ & b.d.l. \\
\hline Ser & $11.70 \pm 1.24$ & b.d.l. \\
\hline Gly & $40.30 \pm 3.96$ & b.d.l. \\
\hline His & $20.44 \pm 2.01$ & b.d.l. \\
\hline Arg & $26.24 \pm 3.02$ & b.d.l. \\
\hline Thr & $1.10 \pm 0.1$ & b.d.l. \\
\hline Ala & $113.42 \pm 10.75$ & $13.4 \pm 1.55$ \\
\hline Pro & $159.54 \pm 14.44$ & $8.9 \pm 0.9$ \\
\hline Tyr & $87.47 \pm 7.97$ & $11.3 . \pm 0.98$ \\
\hline Val & $48.96 \pm 5.62$ & b.d.l. \\
\hline $\operatorname{Met}^{a}$ & $18.08 \pm 2.04$ & b.d.l. \\
\hline Cys $^{a}$ & $28.89 \pm 2.51$ & b.d.l. \\
\hline Leu & $85.08 \pm 8.46$ & $2.4 \pm 0.19$ \\
\hline Phe & $47.62 \pm 4.95$ & $4.9 \pm 0.50$ \\
\hline Lys & $14.07 \pm 1.38$ & b.d.l. \\
\hline
\end{tabular}

${ }^{a}$ Sulphur-containing amino acids b.d.l. - below detection limit.

A)

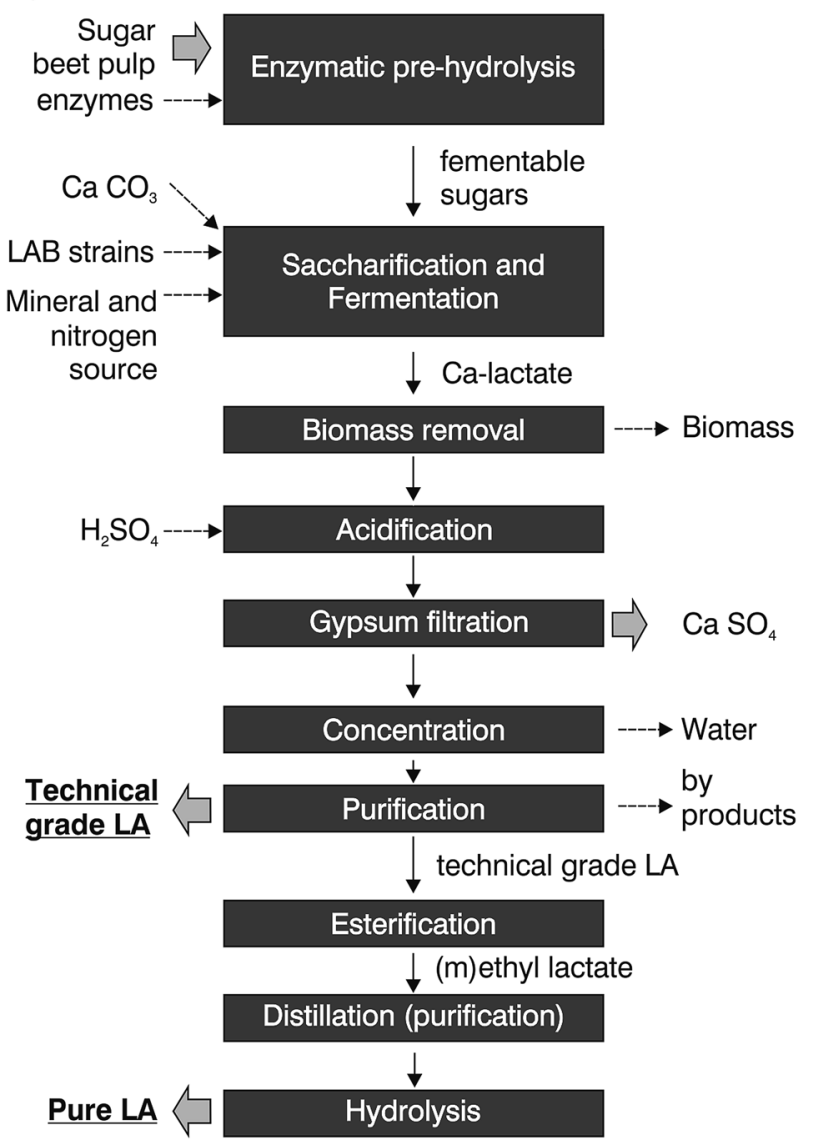

precipitation. Although some of the impurities are removed with the washes, there is also significant loss of calcium lactate. ${ }^{39}$

In our investigations, it was decided to use activated carbon (ERCARBON GE) or a mixture of activated carbon (Ecocarbon GE) and silica (POCH Gliwice SA) as adsorbents. ${ }^{26}$ These effectively removed impurities containing heteroatoms and significantly increased the concentration of lactic ions. Table 4 shows the results of quantitative analysis of amino acids after lactic fermentation in a solution with SBP hydrolyzate. Results for the same solution after purification on activated carbon are also presented. As can be seen, the concentration of total amino acids, particularly those containing sulphur atoms in the amino acid structure, is significantly lower without purification. It can be concluded that the presence of compounds, such as amino acids, which contain heteroatoms $\mathrm{N}$ and $\mathrm{S}$ in the crude fermentation media inhibits the activity of ruthenium catalysts for the reduction of lactate ions.

The effect of different types and amounts of activated carbon and silica on the composition of the post-fermentation media will be in the subject of a subsequent article. Despite recent progress, fermentative production of LA is still costly, mainly due to the complex and diverse purification steps required. ${ }^{41}$

B)

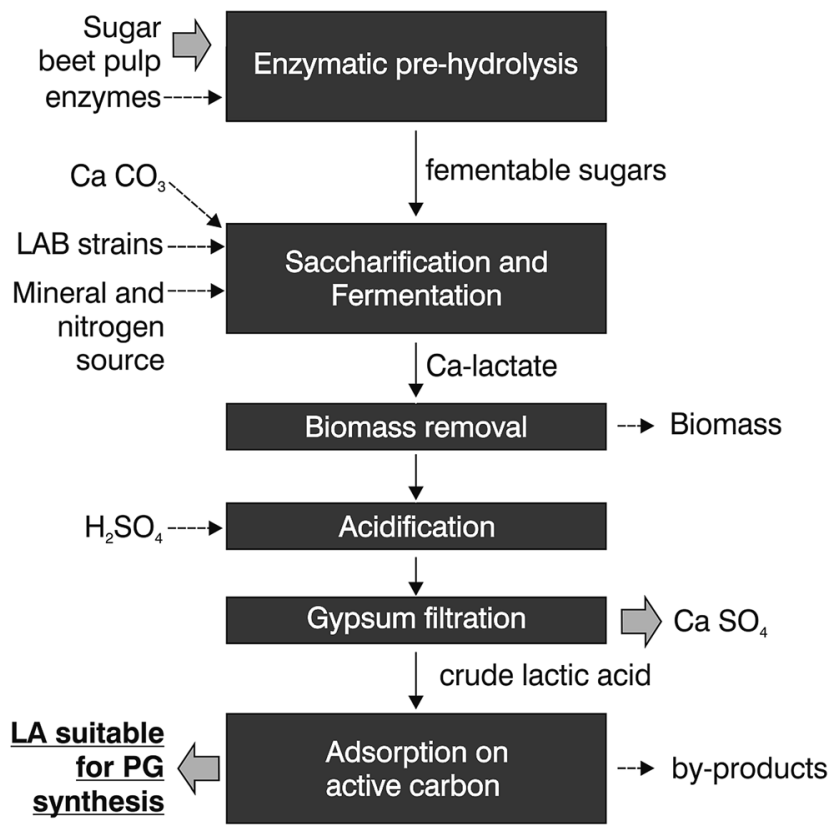

Fig. 1 Simplified block scheme for the fermentative production of LA: (A) - classical procedure (adapted from Dusselier ${ }^{41}$ ); $(B)-$ proposed procedure for PG synthesis. 
Given the increasing use of biobased chemicals, it is important to address this bottleneck. With these factors being considered, the possibility of using SBP for LA fermentation can now be examined (Fig. 1).

Low-lignin SBP biomass does not require special pretreatment. As shown by this study, enzymatic saccharification of SBP can best be achieved through the SSF process. Once the lactate salts reach the required concentration, the medium is filtered (for cell removal) and is sulphuric acid added. In this way, free LA and low-value insoluble salts (mainly $\mathrm{CaSO}_{4}$ ) are formed as by-products. Following the removal of the gypsum, the liquid is further purified and concentrated to obtain technical grade LA. The impure LA can be esterified and subjected to further downstreaming for use in food or solvents. ${ }^{41}$ Catalytic reduction of lactate ions does not require the pure LA to be isolated from the broth nor concentration of the solution. After efficient fermentation, the amounts of unused sugars in the broth are very low, and they do not compete in the reduction reaction. However, all impurities, including sulphur and nitrogen atoms, should be removed, as these can potentially poison the metallic catalysts. Therefore, a simple method for the treatment of postfermentation media with activated carbon (or with a mixture of activated carbon and silica) is proposed (Fig. 1B).

Table 5 Influence of the addition of $\mathrm{H}_{2} \mathrm{SO}_{4}$ to $0.1 \mathrm{M}$ calcium lactate solution on the conversion of lactate ions and selectivity to propylene glycol $^{a}$

\begin{tabular}{lcc}
\hline $\mathrm{pH}$ of solution & $X[\%]$ & $S[\%]$ \\
\hline $7.35 \pm 0.10$ & 0 & 0 \\
$5.50 \pm 0.10$ & 35.5 & 28.2 \\
$4.00 \pm 0.10$ & 71.8 & 50.2 \\
$3.00 \pm 0.10$ & 80.0 & 78.5 \\
$2.50 \pm 0.10$ & 87.3 & 91.1 \\
${ }^{a}$ Reaction conditions: $T=130{ }^{\circ} \mathrm{C}, \mathrm{pH}_{2}=3.5 \mathrm{MPa}, m_{\text {cat }}=0.5 \mathrm{~g}, \mathrm{~V}=20$ \\
mL, $C_{\mathrm{C}_{6} \mathrm{H}_{10} \mathrm{CaO}_{6}}=0.1 \mathrm{M}$.
\end{tabular}

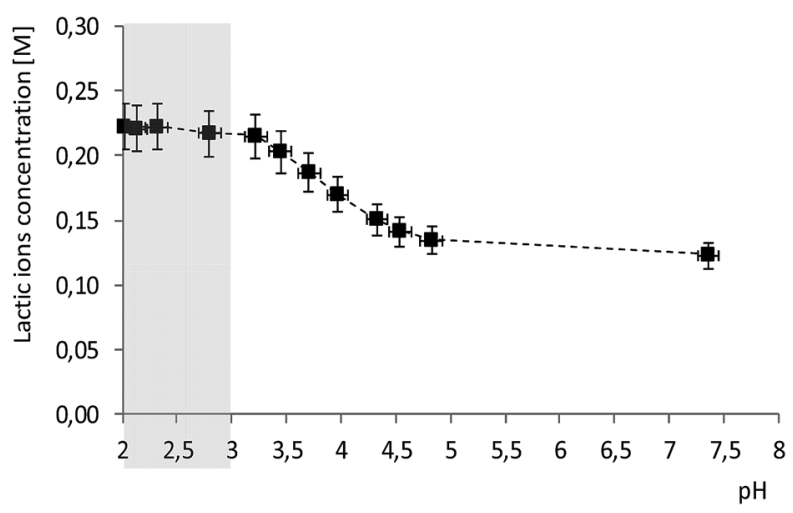

Fig. 2 Changes in the concentration of lactate ions in the solution $\left(\mathrm{C}_{6} \mathrm{H}_{10} \mathrm{CaO}_{6} \mathrm{O} .1 \mathrm{M}\right.$ ) relative to $\mathrm{pH}$ (the amount of concentrated $\mathrm{H}_{2} \mathrm{SO}_{4}$ added).
Table 6 Influence of the addition of $\mathrm{HCl}$ to $0.1 \mathrm{M}$ calcium lactate solution on the conversion of lactate ions and selectivity to propylene glycol

\begin{tabular}{lcc}
\hline $\mathrm{pH}$ of solution & $X[\%]$ & $S[\%]$ \\
\hline $7.35 \pm 0.10$ & 0 & 0 \\
$5.50 \pm 0.10$ & 8.2 & 27.9 \\
$4.00 \pm 0.10$ & 19.6 & 64.4 \\
$3.00 \pm 0.10$ & 35.8 & 74.9 \\
$2.50 \pm 0.10$ & 65.2 & 59.8 \\
$2.00 \pm 0.10$ & 79.4 & 55.7
\end{tabular}

\subsection{Propylene glycol synthesis}

3.3.1. Effect of substrate. Initially, we investigated the suitability of commercial calcium lactate $\left(\mathrm{C}_{6} \mathrm{H}_{10} \mathrm{CaO}_{6}\right.$, POCh S.A, p.p.a.) as a substratum in the production of PG. It was observed that the reduction of $0.1 \mathrm{M}$ solution of $\mathrm{C}_{6} \mathrm{H}_{10} \mathrm{CaO}_{6}$ did not produce PG. The lactate ions were too strongly bound in the salt molecules to be selectively reduced to the desired product (Table 5). However, the addition of strong acid, $\mathrm{H}_{2} \mathrm{SO}_{4}$ (Table 5, Fig. 2) or $\mathrm{HCl}$ (Table 6), led to the formation of free lactate ions, which could be effectively reduced into PG over $5 \% \mathrm{Ru} / \mathrm{C}$ catalyst.

On the basis of the results presented in Tables 5 and 6, it can be concluded that sulphuric acid(vi) is more effective as an acidifying agent than hydrochloric acid. Moreover, the acidification of crude calcium lactate solution with sulphuric acid(vi) is a process already used by industry (Fig. 2). Adding $\mathrm{H}_{2} \mathrm{SO}_{4}$ until the $\mathrm{pH}$ of the calcium lactate solution was around $2.5 \div$ 3.0 resulted in almost $90 \%$ substrate conversion, while maintaining more than $90 \%$ selectivity to PG.

We therefore decided to acidify the post-fermentation broth using $\mathrm{H}_{2} \mathrm{SO}_{4}$ to $\mathrm{pH}$ 2-3 prior to purification on activated carbon. The diluted water solution of lactate ions obtained was reduced over commercial Ru-based supported catalyst.

3.3.2. Hydrogenation of lactic ions obtained from fermented sugar beet pulp hydrolyzates. Once the biological samples had been acidified with $\mathrm{H}_{2} \mathrm{SO}_{4}$ and purified on activated carbon, catalytic hydrogenation of lactic ions was performed. The reaction was conducted in a high-pressure batch reactor. Table 7 shows a comparison of lactic ion conversions over ruthenium-supported catalyst after $4 \mathrm{~h}$. The activity of the $5 \% \mathrm{Ru} / \mathrm{C}$ catalyst was determined as the percentage of lactate ions converted, according to the equation:

$$
X=\left[1-\left(C / C_{0}\right)\right] \times 100 \%
$$

where: $X$ is the percentage of the lactate ions converted [\%]; $C_{0}$ is the initial concentration of lactate ions $[\mathrm{M}] ; C$ is the concentration of lactate ions at time $t[\mathrm{M}]$.

Selectivity to PG was determined using the equation:

$$
S=\left[C_{\mathrm{PG}} /\left(C_{0}-\mathrm{C}\right)\right] \times 100 \%
$$

where $C_{\mathrm{PG}}$ is the concentration of PG [M].

The reaction conditions were optimized in terms of time and weight of catalyst to achieve a concentration of lactic ions of 
Table 7 Activity and selectivity of $5 \%$ Ru/C catalyst for reduction of lactate ions to propylene glycol

\begin{tabular}{|c|c|c|c|c|c|c|}
\hline Biological substratum & $\mathrm{pH}$ & $\begin{array}{l}\text { Initial concentration } \\
\text { of lactate ions }[\mathrm{M}]\end{array}$ & $\begin{array}{l}\text { Final concentration } \\
\text { of lactate ions }[\mathrm{M}]\end{array}$ & $\begin{array}{l}\text { Conversion of } \\
\text { lactate ions [\%] }\end{array}$ & $\begin{array}{l}\text { Concentration of } \\
\text { propylene glycol }[\mathrm{M}]\end{array}$ & $\begin{array}{l}\text { Selectivity to } \\
\text { propylene glycol [\%] }\end{array}$ \\
\hline $\begin{array}{l}\text { Lactobacillus delbrueckii } \\
\text { PCM } 490\end{array}$ & $2.5 \pm 0.2$ & $0.488 \pm 0.024$ & $0.049 \pm 0.002$ & 89.96 & $0.428 \pm 0.034$ & 97.49 \\
\hline Lactococcus lactis PCM 2379 & $2.5 \pm 0.2$ & $0.464 \pm 0.23$ & $0.211 \pm 0.011$ & 54.53 & $0.173 \pm 0.014$ & 68.38 \\
\hline Lactobacillus plantarum HII & $2.5 \pm 0.2$ & $0.556 \pm 0.028$ & $0.307 \pm 0.015$ & 44.78 & $0.238 \pm 0.019$ & 95.58 \\
\hline Lactobacillus acidophilus & $2.5 \pm 0.2$ & $0.631 \pm 0.032$ & $0.370 \pm 0.019$ & 41.36 & $0.256 \pm 0.020$ & 98.08 \\
\hline $\begin{array}{l}\text { PCM } 2510 \text { and Lactobacillus } \\
\text { plantarum AXG }\end{array}$ & $2.5 \pm 0.2$ & $0.523 \pm 0.026$ & $0.323 \pm 0.016$ & 38.24 & $0.134 \pm 0.011$ & 67.00 \\
\hline Lactococcus lactis PCM & $2.5 \pm 0.2$ & $0.809 \pm 0.040$ & $0.483 \pm 0.024$ & 40.30 & $0.143 \pm 0.011$ & 43.87 \\
\hline $\begin{array}{l}2379 \text { and Lactobacillus } \\
\text { plantarum } \mathrm{AXD}\end{array}$ & $2.5 \pm 0.2$ & $0.492 \pm 0.025$ & $0.243 \pm 0.012$ & 50.61 & $0.210 \pm 0.017$ & 84.34 \\
\hline
\end{tabular}

around $0.5 \mathrm{M}$. Biological samples with higher concentrations of lactic ions were diluted to $0.5 \mathrm{M}$. The $0.5 \mathrm{~g}$ ruthenium catalyst showed similar activity and selectivity with diluted biological samples to that observed for $0.5 \mathrm{M}$ solution of commercial LA after $4 \mathrm{~h}$ of hydrogenation. ${ }^{26}$ This result proves the effectiveness of the method of purification used on the biological samples prior to the catalytic process.

\section{Conclusions}

This study has proposed a new method for the treatment of post-fermentation broth containing calcium lactate, obtained from SBP. The post-fermentation broth was acidified to $\mathrm{pH} 2-3$ and purified using activated carbon. Catalytic reduction of a diluted water solution of LA was performed over Ru-based supported catalyst. The yield of PG was satisfactory. Propylene glycol is an example of a product derived from LA with a rapidly growing market. The water solutions of PG obtained using our method could be used in concentrated form as a component in antifreeze.

\section{Acknowledgements}

The authors would like to acknowledge the contribution of the National Centre for Research and Development funded Applied Research Programme - Project "Sugar beet pulp biomass as a raw material for new fermentation media” PBS1/B8/3/2012.

\section{Notes and references}

1 Ch. Gao, C. Ma and P. Xu, Biotechnol. Adv., 2011, 29, 930-939. 2 P. Pal, J. Sikder, S. Roy and L. Giorno, Chem. Eng. Prog., 2009, 48, 1549-1559.

3 E. Brown and H. Adkins, J. Am. Chem. Soc., 1934, 56, 3689. 4 H. Adkins and A. Pavlic, J. Am. Chem. Soc., 1947, 69, 3039.

5 H. Adkins and H. Billica, J. Am. Chem. Soc., 1948, 70, 3121. 6 H. Broadbent, G. Campbell, W. Bartley and J. Johnson, J. Org. Chem., 1959, 24, 1847.

7 T. Ford, US Pat., 2,607,807, 1952.
8 J. Carnahan, T. Ford, W. Gresham, W. Grisby and G. Hager, J. Am. Chem. Soc., 1955, 77, 3766.

9 Z. Zhang, J. E. Jackson and D. J. Miller, Appl. Catal., A, 2001, 219, 89.

10 T. Y. Jang, K. B. Song, H. R. Eom, D. K. Noh, I. K. Song, J. Yi and S.-H. Baeck, Res. Chem. Intermed., 2011, 37, 1275.

11 H. Jang, S.-H. Kim, D. Lee, S. E. Shim, S.-H. Baeck, B. S. Kim and T. S. Chang, J. Mol. Catal. A: Chem., 2013, 380, 57.

12 R. D. Cortright, M. Sanchez-Castillo and J. A. Dumesic, Appl. Catal., B, 2002, 39, 353.

13 D. Y. Murzin and I. L. Simakova, Catal. Ind., 2011, 3(3), 218. 14 M. N. Simonov, I. L. Simakova, T. P. Minyukova and A. A. Khasin, Izv. Akad. Nauk, Ser. Khim., 2009, 6, 1086.

15 M. N. Simonov, I. L. Simakova and V. N. Parmon, React. Kinet. Catal. Lett., 2009, 97, 157.

16 M. N. Simonov, P. A. Zaikin and I. L. Simakova, Appl. Catal., $B$, 2012, 119-120, 340.

17 I. L. Simakova, M. N. Simonov, M. P. Demeshkina, T. P. Minyukova, A. A. Khassin and V. N. Parmon, WO Patent 2009103682, 2009.

18 R. Datta and M. Henry, J. Chem. Technol. Biotechnol., 2006, 81, 1119.

19 J. Vijayakumar, R. Aravindan and T. Viruthagiri, Chem. Biochem. Eng. Q., 2008, 22(2), 245-264.

20 A. Corma, S. Iborra and A. Velty, Chem. Rev., 2007, 107, 2411. 21 Z. Zhang, J. E. Jackson and D. J. Miller, Bioresour. Technol., 2008, 99, 5873.

22 F. A. C. Martinez, E. M. Balciunas, J. M. Salgado, J. M. D. Gonzalez, A. Converti and R. Pinheiro de Souza Oliveira, Trends Food Sci. Technol., 2013, 30(19), 70.

23 H. G. Joglekar, I. Rahman, S. Babu, B. D. Kulkarni and A. Joshi, Sep. Purif. Technol., 2006, 52, 1-17.

24 R. P. John, G. S. Anisha, K. Madhavan Nampoothiri and A. Pandey, Biotechnol. Adv., 2009, 27, 145.

25 T. Ghaffar, M. Irshad, Z. Anwar, T. Aqil, Z. Zulifqar, A. Tariq, M. Kamran, N. Ehsan and S. Mehmood, J. Radiat. Res. Appl. Sci., 2014, 7, 222-229.

26 J. Berlowska, M. Binczarski, M. Dudkiewicz, H. Kalinowska, I. A. Witonska and A. V. Stanishevsky, RSC Adv., 2015, 5, 2299. 
27 P. von Frieling and K. Schugerl, Process Biochem., 1999, 34, 685-696.

28 M. Besson, P. Gallezot and C. Pinel, Chem. Rev., 2014, 114, 1827.

29 R. P. John, K. Madhavan Nampoothiri and A. Pandey, Appl. Microbiol. Biotechnol., 2007, 74, 524-534.

30 J. Deutcher, Curr. Opin. Microbiol., 2008, 11, 87-93.

31 Y. Wang, Y. Tashiro and K. Sonomoto, J. Biosci. Bioeng., 2015, 119, 10-18.

32 K. Hofvendahl and B. Hahn-Hagerdal, Enzyme Microb. Technol., 2000, 26, 87-107.

33 Y. Zhang, X. Chen, J. Luo, B. Qi and Y. Wan, Bioresour. Technol., 2014, 158, 396-399.

34 A. Nancib, N. Nancib and J. Boudrant, World J. Microbiol. Biotechnol., 2009, 25, 1423-1429.
35 F. Cui, Y. Li and C. Wan, Bioresour. Technol., 2011, 102, 18311836.

36 K. B. Lee, Process Biochem., 2005, 40, 1559-1564.

37 A. N. Vaidya, R. A. Pandey, S. Mudliar, M. Suresh Kumar, T. Chakrabarti and S. Devotta, Crit. Rev. Environ. Sci. Technol., 2005, 35(5), 429-467.

38 Y. Zhang, L. Ma and J. Yang, React. Funct. Polym., 2004, 61(1), 101-114.

39 H. G. Joglekar, I. Rahman, S. Babu, B. D. Kulkarni and A. Joshi, Sep. Purif. Technol., 2006, 52, 1-17.

40 X. Sun, Q. Wang, W. Zhao, H. Ma and K. Sakata, Sep. Purif. Technol., 2006, 49, 43-48.

41 M. Dusselier, P. Van Wouwe, A. Dewaele, E. Makshina and B. F. Sels, Energy Environ. Sci., 2013, 6, 1415-1442. 